\title{
SMR
}

\section{Pterostilbene as treatment for severe acute} pancreatitis

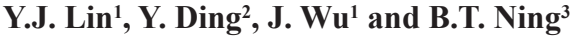 \\ ${ }^{1}$ Department of Intensive Care, Sir Run Run Shaw Hospital, \\ Medicine School of Zhejiang University, Hangzhou, China \\ ${ }^{2}$ Department of Emergency, Hangzhou Xiasha Hospital, Hangzhou, China \\ ${ }^{3}$ Pediatric Intensive Care Unit, Children's Hospital, \\ Medicine School of Zhejiang University, Hangzhou, China \\ Corresponding author: B.T. Ning \\ E-mail: ningbotao122@sina.com
}

Genet. Mol. Res. 15 (3): gmr. 15038330

Received December 22, 2015

Accepted May 5, 2016

Published August 12, 2016

DOI http://dx.doi.org/10.4238/gmr.15038330

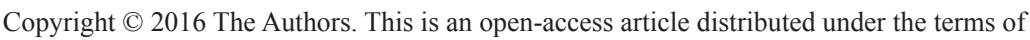
the Creative Commons Attribution ShareAlike (CC BY-SA) 4.0 License.

\begin{abstract}
Acute pancreatitis (AP) has a fast onset and progression, which lead to an unfavorable prognosis. Therefore, the development of novel drugs for its treatment is critical. As a homologous derivative of resveratrol, pterostilbene exerts a variety of effects including anti-inflammatory, antioxidant, and antitumor effects. This study investigated the potential of pterostilbene for treatment of severe AP (SAP) and related mechanisms. Effects of pterostilbene were evaluated in a Wistar rat model of AP. Serum levels of amylase (AMY), creatinine $(\mathrm{Cr})$, and alanine aminotransferase (ALT) were quantified. Furthermore, serum levels of tumor necrosis factor (TNF)- $\alpha$ and interleukin (IL)- $1 \beta$ were quantified using enzyme-linked immunosorbent assay. Nuclear factor (NF)- $\kappa \mathrm{B}$ expression in pancreatic tissues was quantified by realtime PCR and western blotting. The production of reactive oxygen species (ROS) was determined using a spectrometer, while superoxide
\end{abstract}


dismutase (SOD) activity was assayed. In the AP rat model, the expression of inflammatory markers TNF- $\alpha$ and IL-1 $\beta$, expression of $\mathrm{NF}-\mathrm{\kappa B}$, and serum indices (AMY, Cr, and ALT) increased compared to the corresponding levels in the control group $(\mathrm{P}<0.05)$. Pterostilbene reduced serum levels of TNF- $\alpha$ and IL- $1 \beta$; decreased NF- $\kappa B$ gene expression, serum indices, and ROS generation; and increased SOD activity in a dose-dependent manner. In conclusion, pterostilbene can alleviate SAP-induced tissue damage by decreasing the inflammatory response and by promoting antioxidation leading to the protection of pancreatic tissues.

Key words: Acute pancreatitis; Pterostilbene; Nuclear factor-кB; Tumor necrosis factor- $\alpha$

\section{INTRODUCTION}

Acute pancreatitis (AP) is the sudden inflammation of the pancreas and has a fast onset (Gooshe et al., 2015). The early manifestations of AP are atypical, mainly including acute upper abdominal pain, nausea, vomiting, and elevated amylase level (Chanana et al., 2015). Mild AP only involves pancreatic edema, and can self-heal in a short time. However, severe AP (SAP) can lead to necrosis of tissues adjacent to the pancreas and to multiple-organ failure in a short time. Due to the fast progression and lack of effective treatment, SAP has unfavorable prognosis and an extremely high mortality rate (Dragoman et al., 2015; Kayar et al., 2015). The pathological features of AP mainly result from the activation of trypsin inside the pancreas, leading to auto-digestion, tissue edema, hemorrhage, and necrotic inflammation (Murata et al., 2015; Usborne et al., 2015). AP may be induced by various factors including bile duct obstruction, alcohol abuse, thrombosis (of lymph vessel, vein, or artery), traumatic injury, and infection. Inflammation is believed to be the initiating factor of AP. It leads to an abnormal activation of trypsin inside the pancreatic acinar cells, which causes systemic reactions (Ehehalt et al., 2015; Nasa et al., 2015). Therefore, the identification of new drugs that are effective against SAP is of great importance for alleviating disease progression and for improving survival rates and prognosis (Puiggròs et al., 2015).

Resveratrol has multiple activities including antioxidant, anti-inflammatory, antibacterial, antitumor, vasodilation modulator, and platelet aggregation inhibitor. In addition, it regulates lipoprotein metabolism and improves the body's immune functions (Yar et al., 2011; Jagadeb et al., 2014; Shimoda et al., 2015). Pterostilbene [(E)-3,5-dimethyl-4-hydroxyl phenyl ethylene] is a 3,5-dimethyl derivative of resveratrol. It is one among the non-flavonoid polyphenol compounds that are found in grapes, nuts, strawberry, Guangxi dragon's blood, and propolia (Hsiao et al., 2014; Sato et al., 2014). Pterostilbene has activities that are similar to those of resveratrol, and shows multiple activities including antifungal, antiproliferative, antioxidant, anti-inflammatory, and antilipidemic activities. However, it has higher bioactivity than resveratrol and mainly exerts anti-inflammatory, antioxidant, and antitumor activities. Studies have shown its efficacy in treating multiple diseases including Alzheimer's disease, cardiovascular disorders, brain trauma, cancer, and hypercholesterolemia (Pan et al., 2014; Saw et al., 2014). Therefore, this study investigated the protective role of pterostilbene against SAP and related mechanisms.

Genetics and Molecular Research 15 (3): gmr.15038330 


\section{MATERIAL AND METHODS}

\section{Animal model}

Healthy male Wistar rats $(\mathrm{N}=40$, age $=2$ months, body weight $=250 \mathrm{~g})$ were purchased from the Laboratory Animal Unit of Medicine School of Zhejiang University and were kept in an SPF facility. The room temperature was maintained at $21^{\circ} \pm 1{ }^{\circ} \mathrm{C}$, and the relative humidity at 50 to $70 \%$. A 12-h light/12-h dark cycle was maintained throughout the study.

All experimental procedures were approved by the Animal Ethics Committee of Medicine School of Zhejiang University. All animal experiments followed the animal care guidelines of Zhejiang University.

Animals were randomly divided into 4 groups $(\mathrm{N}=10)$ : control, SAP, low pterostilbene $(20 \mathrm{mg} / \mathrm{kg})$, and high pterostilbene $(40 \mathrm{mg} / \mathrm{kg}$ ). SAP was induced in all groups except the control group. For development of SAP model, the rats were fasted for $12 \mathrm{~h}$, and anesthetized by intraperitoneal injection of $10 \%$ chloral hydrate. A median incision was made in the upper abdomen to expose the duodenum and biliary pancreatic duct that was then clipped on the proximal site of the hepatic portal. A retrograde puncture was made on the biliary pancreatic duct via duodenal papilla. Subsequently, freshly prepared 5\% sodium taurocholate solution (Sigma, USA) was perfused into the biliary pancreatic duct at $0.1 \mathrm{~mL} / \mathrm{min}$ to reach an internal concentration of $0.1 \mathrm{mg} / 100 \mathrm{~g}$ as previously described (Wang et al., 2015b). The biliary duct was then clipped for $5 \mathrm{~min}$ to immerse all pancreatic lobes into sodium taurocholate solutions. In the control group, a similar surgical procedure was performed; however, equal volume of saline was applied instead of sodium taurocholate solution. The two treatment groups received 20 or $40 \mathrm{mg} / \mathrm{kg}$ pterostilbene (Gómez-Zorita et al., 2015) before surgery.

\section{Determination of serum AMY, Cr and ALT}

Blood samples were collected from the abdominal aorta. After incubation at room temperature for $30 \mathrm{~min}$, serum was collected by centrifugation at $2000 \mathrm{~g}$ for $10 \mathrm{~min}$. Serum levels of AMY, Cr, and ALT were determined using an automatic biochemical analyzer.

\section{Enzyme-linked immunosorbent assay (ELISA)}

Serum samples were assayed for inflammatory cytokines (TNF- $\alpha$ and IL-1 $\beta$ ) using ELISA kits. Briefly, serially diluted standards and samples were added to the 96-well plates in triplicate. Enzyme-labeling reagents $(50 \mu \mathrm{L})$ were then added to each well and plates were incubated for $30 \mathrm{~min}$ at $37^{\circ} \mathrm{C}$. Subsequently, chromogenic substrates A and B (50 $\mu \mathrm{L}$ each) were added and plates were incubated in the dark at $37^{\circ} \mathrm{C}$ for $10 \mathrm{~min}$ to develop signals. The reaction was quenched by addition of a stopping buffer. Plates were read on a microplate reader (BD, USA) to record the optical density values at $450 \mathrm{~nm}$. A standard curve was used to determine the sample values using linear regression.

\section{Real-time PCR}

Pancreatic tissues were collected, rinsed in PBS, and homogenized on ice. The mRNA was extracted using Trizol reagent (Invitrogen, USA) and converted to cDNA using specific

Genetics and Molecular Research 15 (3): gmr.15038330 
primers (Table 1). Real-time PCR was performed to detect the expression of target genes under the following conditions: $95^{\circ} \mathrm{C}$ for $1 \mathrm{~min}$; followed by 35 cycles of denaturing at $90^{\circ} \mathrm{C}$ for $30 \mathrm{~s}$; annealing at $58^{\circ} \mathrm{C}$ for $50 \mathrm{~s}$; and elongation at $72^{\circ} \mathrm{C}$ for $35 \mathrm{~s}$. Fluorescence signals were detected and the $\mathrm{Ct}$ values were analyzed with reference to GAPDH. Relative expression was determined by the $2^{-\Delta \mathrm{Ct}}$ method.

Table 1. Primer sequences.
\begin{tabular}{l|l|l}
\hline Target gene & Forward primer (5'-3') & Reverse primer $\left(5^{\prime}-3^{\prime}\right)$ \\
\hline GAPDH & AGTGCCAGCCTCGTCTCATAG & CGTTGAACTTGCCGTGGGTAG \\
\hline NF-KB & CTCATCTAAGCGGAACAATGG & GCACATTCTCTCCGTAGCG \\
\hline
\end{tabular}

\section{Western blotting}

Pancreatic tissues were homogenized and a lysis buffer was added to extract the total proteins. The homogenized tissue samples were then ruptured by ultrasonication and centrifuged at $10,000 \mathrm{~g}$ for $15 \mathrm{~min}$. Proteins were collected and stored at $-20^{\circ} \mathrm{C}$. For western blotting, proteins were resolved by $10 \%$ SDS-PAGE, and then transferred to a PVDF membrane (Pall Life, USA). Non-specific binding sites were blocked by incubation in $5 \%$ non-fat milk powder for $2 \mathrm{~h}$. The membranes were then incubated with anti-NF- $\mathrm{kB}$ monoclonal antibody (1:1000, Cell Signaling, USA) overnight. Subsequently, the membranes were incubated with goat anti-rabbit IgG (1:2000, Cell Signaling) antibody for $30 \mathrm{~min}$. The membranes were washed with PBST, exposed to ECL reagents, and imaged. An image-analyzing system was then used to detect the density of bands with repeated measures $(\mathrm{N}=4)$.

\section{Superoxide dismutase (SOD) activity assay}

SOD activity was evaluated using an SOD activity assay kit (Jiancheng Biotech, China) following the manufacturer protocol. Briefly, the tissue proteins were denatured at $95^{\circ} \mathrm{C}$ for $40 \mathrm{~min}$, and centrifuged at $2000 \mathrm{~g}$ for $10 \mathrm{~min}$. SOD was prepared by extraction with chloroform-ethanol $(5: 3, \mathrm{v} / \mathrm{v})$, centrifugation and acetone precipitation. SOD activity was measured based on the xanthine oxidase method.

\section{Determination of ROS}

Pancreatic tissues were processed as described for the SOD assay, and incubated with $2^{\prime}, 7^{\prime}$-dichlorofluorescein diacetate for $15 \mathrm{~min}$. After incubation, the samples were centrifuged and the precipitated pellets were re-suspended in sterile PBS. Samples were then incubated at $37^{\circ} \mathrm{C}$ for $60 \mathrm{~min}$. The ROS level was quantified by spectrometry and reported as percentage.

\section{Statistical analysis}

The data are reported as means \pm standard deviation (SD). The SPSS 16.0 software was used to analyze all data. Analysis of variance (ANOVA) was used to compare the means across groups. A statistical significance was defined when $\mathrm{P}<0.05$.

Genetics and Molecular Research 15 (3): gmr.15038330 


\section{RESULTS}

\section{Serum indices of rats}

The levels of AMY, Cr, and ALT in the SAP model rat group were significantly higher than in the control group (Table 2; $\mathrm{P}<0.05$ ) after $12 \mathrm{~h}$ of SAP induction. The administration of pterostilbene significantly depressed these indices compared to the model group in a dose-dependent manner (Table 2; $\mathrm{P}<0.05$ ), although the indices were still higher than in the control group.

Table 2. Serum indices of all rats.

\begin{tabular}{l|c|c|c|c}
\hline Index & Control & SAP model & Pterostilbene $(20 \mathrm{mg} / \mathrm{kg})$ & Pterostilbene $(40 \mathrm{mg} / \mathrm{kg})$ \\
\hline AMY(U/L) & $1520 \pm 216$ & $7617 \pm 378^{*}$ & $4659 \pm 232^{* \#}$ & $3159 \pm 345^{* \# \Delta}$ \\
\hline ALT (U/L) & $118 \pm 13.2$ & $342 \pm 31.2^{*}$ & $255 \pm 12.1^{* \#}$ & $186 \pm 22.4^{* \# \Delta}$ \\
\hline Cr (U/L) & $32 \pm 2.1$ & $97 \pm 3.6^{*}$ & $71 \pm 6.6^{* \#}$ & $51 \pm 4.3^{* \# \Delta}$ \\
\hline
\end{tabular}

$* \mathrm{P}<0.05$ compared to the control group; ${ }^{\mathrm{P}}<0.05$ compared to the $\mathrm{SAP}$ group; $\triangle \mathrm{P}<0.05$ compared to $20 \mathrm{mg} / \mathrm{kg}$ pterostilbene group.

\section{Effects of pterostilbene on inflammatory markers TNF- $\alpha$ and IL-1 $\beta$}

Serum levels of TNF- $\alpha$ and IL-1 $\beta$ were higher in the SAP model rats than in the control group $(\mathrm{P}<0.05)$ as determined by ELISA. Pterostilbene significantly suppressed the expression of serum TNF- $\alpha$ and IL-1 $\beta$ in a dose-dependent manner $(\mathrm{P}<0.05$; Figure 1$)$, although the expression was still higher than that in the control group. These results collectively suggested the role of pterostilbene in decreasing serum inflammatory cytokine secretion for alleviating inflammation in SAP.
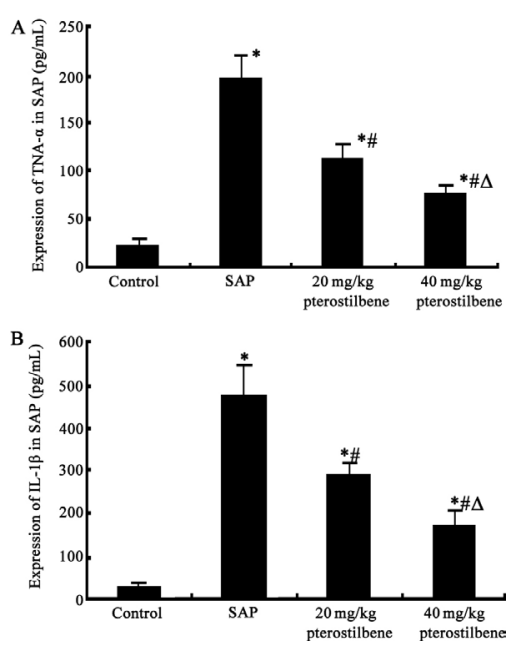

Figure 1. Effects of pterostilbene on serum inflammatory cytokines, TNF- $\alpha$ and IL-1 $\beta$, in SAP rats. A. TNF- $\alpha$, B. IL-1 $\beta .{ }^{*} \mathrm{P}<0.05$ compared to the control group; ${ }^{*} \mathrm{P}<0.05$ compared to the $\mathrm{SAP}$ group; ${ }^{\wedge} \mathrm{P}<0.05$ compared to 20 $\mathrm{mg} / \mathrm{kg}$ pterostilbene group.

Genetics and Molecular Research 15 (3): gmr.15038330 


\section{Effects of pterostilbene on NF- $\mathrm{KB}$ expression in pancreatic tissue}

Real-time PCR showed that NF- $\kappa B$ expression was increased in the SAP rat pancreas than in the pancreas of control group rats $(\mathrm{P}<0.05$; Figure 2$)$. The pre-treatment with pterostilbene significantly inhibited NF- $\mathrm{kB}$ expression. However, at high dose it only marginally potentiated such inhibitory effects without statistical significance $(\mathrm{P}>0.05$; Figure 2$)$.

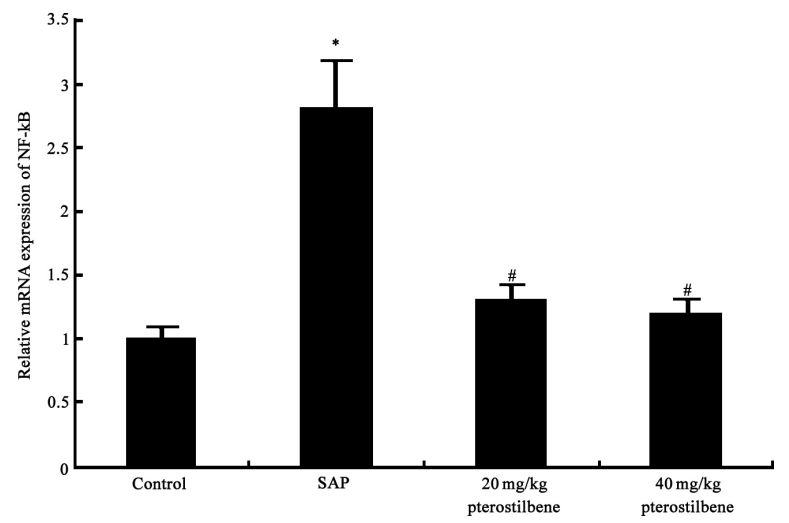

Figure 2. NF- $\kappa \mathrm{B}$ mRNA expression in pancreatic tissues. ${ }^{*} \mathrm{P}<0.05$ compared to the control group; ${ }^{*} \mathrm{P}<0.05$ compared to the SAP group.

\section{NF-KB protein expression}

Western blotting showed that NF- $\kappa B$ protein expression was consistent with the mRNA expression patterns. NF- $\kappa$ B protein was significantly up-regulated in SAP rats $(\mathrm{P}<0.05$; Figure $3)$. Pre-treatment with pterostilbene significantly inhibited NF- $\kappa B$ expression. However, this inhibition was not in a dose-dependent manner, as at high doses it only marginally potentiated such inhibitory effects without statistical significance $(\mathrm{P}>0.05$; Figure 3$)$.

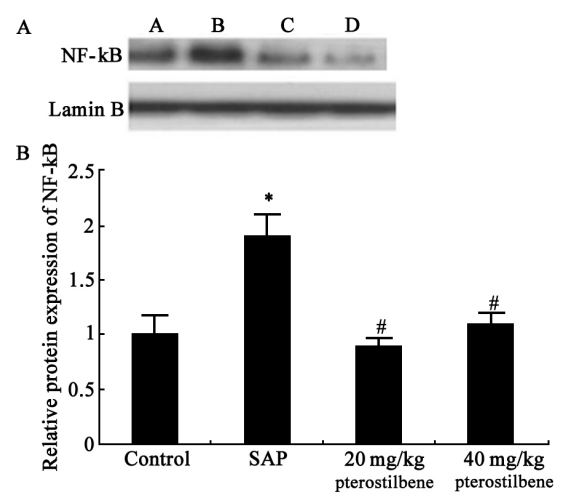

Figure 3. Effect of pterostilbene on NF-кB protein expression. A. Representative western blotting bands. Lane A, control group; lane $B$, SAP model group; lane $C, 20 \mathrm{mg} / \mathrm{kg}$ pterostilbene group; lane $D, 40 \mathrm{mg} / \mathrm{kg}$ pterostilbene group. B. Quantitative analysis of NF- $\mathrm{KB}$ levels. ${ }^{*} \mathrm{P}<0.05$ compared to the control group; ${ }^{\#} \mathrm{P}<0.05$ compared to the SAP group.

Genetics and Molecular Research 15 (3): gmr.15038330 


\section{Oxidative stress indices}

The ROS generation in SAP rats was significantly increased, whereas the SOD contents were decreased compared to in the control group $(\mathrm{P}<0.05)$. The pre-treatment with pterostilbene significantly decreased the ROS production and increased the SOD contents in a dose-dependent manner $(\mathrm{P}<0.05$; Table 3$)$. These results suggested that pterostilbene has potential of protecting pancreatic tissues during SAP by modulating oxidative stress and inhibiting the inflammatory response.

Table 3. Oxidative stress indices in pancreatic tissues.
\begin{tabular}{|c|c|c|c|c}
\hline Index & Control & SAP model & Pterostilbene $(20 \mathrm{mg} / \mathrm{kg})$ & Pterostilbene $(40 \mathrm{mg} / \mathrm{kg})$ \\
\hline ROS & $56 \pm 14$ & $367 \pm 67^{*}$ & $259 \pm 31^{* *}$ & $167 \pm 42^{* * \Delta}$ \\
\hline SOD & $137 \pm 23$ & $41 \pm 6^{*}$ & $85 \pm 12^{* *}$ & $107 \pm 21^{* * \Delta}$ \\
\hline
\end{tabular}

${ }^{*} \mathrm{P}<0.05$ compared to the control group; ${ }^{*} \mathrm{P}<0.05$ compared to the $\mathrm{SAP}$ group; ${ }^{\triangle} \mathrm{P}<0.05$ compared to $20 \mathrm{mg} / \mathrm{kg}$ pterostilbene group.

\section{DISCUSSION}

Among a series of pathological processes induced by SAP, systematic inflammatory response syndrome (SIRS), infectious necrosis, and multiple-organ failure are major factors causing death. Various studies have shown the occurrence of tissue edema, necrosis, and infiltration, all of which facilitate the release of inflammatory cytokines and reduce the expression of anti-inflammatory factors from lymphocytes, neutrophils, and macrophages, disrupt the body's immune balance, and lead to death by SIRS and multiple-organ failure (Liu et al., 2015; Meher et al., 2015). Therefore, inflammation is the main pathological manifestation of SAP. As liver tissue may be severely damaged by SAP, enzymes synthesized in hepatocytes may be released in systemic circulation, causing elevated serum AMY, Cr, and ALT levels (Chen et al., 2015). Consistent with these findings, serum indices and inflammatory cytokines were increased in SAP rats in the current study, suggesting higher inflammation, liver dysfunction, and imbalanced serum indices compared to the control group.

This study showed that pterostilbene decreased the serum levels of TNF- $\alpha$ and IL-1 $\beta$, AMY, Cr, and ALT levels, decreased the ROS generation, and increased the SOD activity. It shows that pterostilbene may alleviate the SAP-related tissue injuries. Previous studies have shown that pterostilbene exerts ROS scavenging activity via antioxidant pathway, which modulates oxidation-reduction homeostasis. In addition, it shows efficacy against multiple diseases including ischemia-reperfusion damage, inflammation, and tumors. In vivo studies showed the effect of pterostilbene in reducing xanthine oxidase expression and improving ischemic injury of renal, testicular, muscular, ovarian, spinal cord, and brain tissues (Chen et al., 2015; El-Sayed et al., 2015). Hence, the results of this study were consistent with previous studies. To the best of our knowledge, this is the first report of using pterostilbene as antiinflammatory agent against SAP. Endogenous antioxidation system continuously clears the ROS to protect tissues from oxidative injury. SOD is one of the most important antioxidative enzymes, which clear oxygen-free radicals. It plays a critical role in maintaining the body's balance of oxidation and antioxidation and its activity directly reflects the body's ability to clear free radicals (Wang et al., 2015c). This study showed that pterostilbene reduced the oxidative injury in pancreatic tissues by up-regulating SOD that facilitated in ROS scavenging activity.

Genetics and Molecular Research 15 (3): gmr.15038330 
$\mathrm{NF}-\kappa \mathrm{B}$ exists silently in cytoplasm under normal circumstances. However, it is activated by transcriptional/translational factors under various stimuli such as inflammatory factors, signal transduction, reactive oxygen family, heavy metals, NO, and interleukins (Wang et al., 2015a). Pterostilbene decreased the expression of NF- $\kappa B$ that reduced inflammation and ROS. However, whether the above changes lead to amelioration of AP inflammatory pathology after administration of pterostilbene was not determined, which could be the main limitation of the current study.

In summary, pterostilbene decreases the SAP-induced pancreatic tissue by alleviating inflammation and antioxidation functions.

\section{Conflicts of interest}

The authors declare no conflict of interest.

\section{ACKNOWLEDGMENTS}

We thank the anonymous reviewers for reviewing this manuscript.

\section{REFERENCES}

Chanana L, Jegaraj MA, Kalyaniwala K, Yadav B, et al. (2015). Clinical profile of non-traumatic acute abdominal pain presenting to an adult emergency department. J. Family Med. Prim. Care 4: 422-425.http://dx.doi.org/10.4103/2249$\underline{4863.161344}$

Chen XW, He ZX, Zhou ZW, Yang T, et al. (2015). An update on the clinical pharmacology of the dipeptidyl peptidase 4 inhibitor alogliptin used for the treatment of type 2 diabetes mellitus. Clin. Exp. Pharmacol. Physiol. 42: 1225-1238. http://dx.doi.org/10.1111/1440-1681.12469

Dragoman M, Curtis KM and Gaffield ME (2015). Combined hormonal contraceptive use among women with known dyslipidemias: a systematic review of critical safety outcomes. Contraception S0010-7824(15)00509-0.

Ehehalt F, Sturm D, Rösler M, Distler M, et al. (2015). Blood glucose homeostasis in the course of partial pancreatectomyevidence for surgically reversible diabetes induced by cholestasis. PLoS One 10: e0134140. http://dx.doi.org/10.1371/ journal.pone. 0134140

El-Sayed SM, Mansour AM and Nady ME (2015). Protective effects of pterostilbene against acetaminophen-induced hepatotoxicity in rats. J. Biochem. Mol. Toxicol. 29: 35-42. http://dx.doi.org/10.1002/jbt.21604

Gómez-Zorita S, Fernández-Quintela A, Aguirre L, Macarulla MT, et al. (2015). Pterostilbene improves glycaemic control in rats fed an obesogenic diet: involvement of skeletal muscle and liver. Food Funct. 6: 1968-1976. http://dx.doi. org $/ 10.1039 / \mathrm{C} 5 \mathrm{FO} 00151 \mathrm{~J}$

Gooshe M, Abdolghaffari AH, Nikfar S, Mahdaviani P, et al. (2015). Antioxidant therapy in acute, chronic and postendoscopic retrograde cholangiopancreatography pancreatitis: An updated systematic review and meta-analysis. World J. Gastroenterol. 21: 9189-9208. http://dx.doi.org/10.3748/wjg.v21.i30.9189

Hsiao PC, Chou YE, Tan P, Lee WJ, et al. (2014). Pterostilbene simultaneously induced G0/G1-phase arrest and MAPKmediated mitochondrial-derived apoptosis in human acute myeloid leukemia cell lines. PLoS One 9: e105342.http:// dx.doi.org/10.1371/journal.pone.0105342

Jagadeb M, Konkimalla VB, Rath SN and Das RP (2014). Elucidation of the inhibitory effect of phytochemicals with Kir6.2 wild-type and mutant models associated in type-1 diabetes through molecular docking approach. Genomics Inform. 12: 283-288. http://dx.doi.org/10.5808/GI.2014.12.4.283

Kayar Y, Turkdogan KA, Baysal B, Gultekin N, et al. (2015). Concurrent acute pancreatitis and pericardial effusion. Pan Afr. Med. J. 21: 122. http://dx.doi.org/10.11604/pamj.2015.21.122.6988

Liu Y, Wang L, Cai Z, Zhao P, et al. (2015). The decrease of peripheral blood CD4+ T cells indicates abdominal compartment syndrome in severe acute pancreatitis. PLoS One 10: e0135768. http://dx.doi.org/10.1371/journal. pone. 0135768

Meher S, Mishra TS, Sasmal PK, Rath S, et al. (2015). Role of biomarkers in diagnosis and prognostic evaluation of acute pancreatitis. J Biomark 2015: 519534. http://dx.doi.org/10.1155/2015/519534

Genetics and Molecular Research 15 (3): gmr.15038330 
Murata A, Ohtani M, Muramatsu K and Matsuda S (2015). Influence of comorbidity on outcomes of older patients with acute pancreatitis based on a national administrative database. HBPD INT 14: 422-428. http://dx.doi.org/10.1016/ $\underline{\text { S1499-3872(15)60398-8 }}$

Nasa P, Alexander G, Kulkarni A, Juneja D, et al. (2015). Early plasmapheresis in patients with severe hypertriglyceridemia induced acute pancreatitis. Indian J. Crit. Care Med. 19: 487-489. http://dx.doi.org/10.4103/0972-5229.162472

Pan C, Hu Y, Li J, Wang Z, et al. (2014). Estrogen receptor- $\alpha 36$ is involved in pterostilbene-induced apoptosis and anti-proliferation in in vitro and in vivo breast cancer. PLoS One 9: e104459. http://dx.doi.org/10.1371/journal. pone. 0104459

Puiggròs C, Molinos R, Ortiz MD, Ribas M, et al. (2015). Experience in bedside placement, clinical validity, and cost-efficacy of a self-propelled nasojejunal feeding tube. Nutr. Clin. Pract. 30: 815-823. http://dx.doi. org/10.1177/0884533615592954

Sato D, Shimizu N, Shimizu Y, Akagi M, et al. (2014). Synthesis of glycosides of resveratrol, pterostilbene, and piceatannol, and their anti-oxidant, anti-allergic, and neuroprotective activities. Biosci. Biotechnol. Biochem. 78: 1123-1128. http://dx.doi.org/10.1080/09168451.2014.921551

Saw CL, Guo Y, Yang AY, Paredes-Gonzalez X, et al. (2014). The berry constituents quercetin, kaempferol, and pterostilbene synergistically attenuate reactive oxygen species: involvement of the Nrf2-ARE signaling pathway. Food Chem. Toxicol. 72: 303-311.http://dx.doi.org/10.1016/j.fct.2014.07.038

Shimoda K, Kubota N, Uesugi D, Hamada H, et al. (2015). Synthesis and pharmacological evaluation of glycosides of resveratrol, pterostilbene, and piceatannol. Ann. N. Y. Acad. Sci. 1348: 141-149.http://dx.doi.org/10.1111/nyas.12836

Usborne A, Byrd RA, Meehan J, Blackbourne JL, et al. (2015). An investigative study of pancreatic exocrine biomarkers, histology, and histomorphometry in male Zucker diabetic fatty (ZDF) rats given dulaglutide by subcutaneous injection twice weekly for 13 weeks. Toxicol. Pathol. 43: 1093-1102. http://dx.doi.org/10.1177/0192623315596857

Wang C, Sun H, Song Y, Ma Z, et al. (2015a). Pterostilbene attenuates inflammation in rat heart subjected to ischemiareperfusion: role of TLR4/NF-кB signaling pathway. Int. J. Clin. Exp. Med. 8: 1737-1746.

Wang CL, Li N, Ma T, Zhang P, et al. (2015b). Ulinastatin promotes T lymphocyte apoptosis in rats with severe acute pancreatitis via mitochondrial pathways. Genet. Mol. Res. 14: 5511-5518.http://dx.doi.org/10.4238/2015.May.25.2

Wang W, Ding XQ, Gu TT, Song L, et al. (2015c). Pterostilbene and allopurinol reduce fructose-induced podocyte oxidative stress and inflammation via microRNA-377. Free Radic. Biol. Med. 83: 214-226. http://dx.doi. org/10.1016/j.freeradbiomed.2015.02.029

Yar AS, Menevse S and Alp E (2011). The effects of resveratrol on cyclooxygenase-1 and -2, nuclear factor kappa beta, matrix metalloproteinase-9, and sirtuin 1 mRNA expression in hearts of streptozotocin-induced diabetic rats. Genet. Mol. Res. 10: 2962-2975. http://dx.doi.org/10.4238/2011.November.29.7

Genetics and Molecular Research 15 (3): gmr.15038330 